Check for updates

Cite this: RSC Adv., 2018, 8, 37267

\title{
Development of hyperbranched crosslinkers from bio-derived platform molecules for the synthesis of epoxidised soybean oil based thermosets $\uparrow$
}

\begin{abstract}
Trin Kamjornsupamitr, Andrew J. Hunt (D) and Nontipa Supanchaiyamat (D)*
Bio-based carboxyl-terminated hyperbranched crosslinkers have been synthesised by the facile esterification reaction of glycerol with succinic anhydride (Gly-SA). The Gly-SA crosslinking molecules have a large number of terminal carboxyl groups, which can crosslink through the epoxide of epoxidised soybean oil (ESO), making a highly flexible transparent film with excellent oxidative resistance. The effect of different molecular weights of Gly-SA cured ESO on the thermal and mechanical properties of the resulting films was also investigated. This study demonstrated that an increase in the molecular weights of Gly-SA, led to a decrease in the curing rate of mixtures, whilst the glass transition temperature $\left(T_{g}\right)$ of Gly-SA cured ESO increased due to the incorporation of the bulky crosslinker. The use of a Gly-SA crosslinker prepared at $150{ }^{\circ} \mathrm{C}$, resulted in a film (EGS150) with a tensile strength 13 times greater than of the control film, exhibited more than a $220 \%$ increase in elongation at break and the Young's modulus quadrupled compared to the value obtained for the control sample. It is noteworthy that the tensile strength and elongation at break improved with increasing Gly-SA chain length, suggesting the prepolymerised crosslinkers contribute to the enhanced mechanical properties of the materials.
\end{abstract}

Received 27th August 2018
Accepted 28th October 2018

DOI: $10.1039 / c 8 r a 07133 k$

rsc.li/rsc-advances

\section{Introduction}

The use of bio-based polymers derived from renewable resources have become of interest due to the rapid depletion of crude oil and the potential environmental benefits. ${ }^{1}$ Plant oils are an attractive feedstock due to their low toxicity, competitive cost, high availability and intrinsic renewability. ${ }^{2-5}$ The majority of plant oils are utilised within the food industry except for castor and linseed oils, which are used in non-food applications such as lubricants, surface coatings and plastics. ${ }^{6-8}$ In addition, plant oils have been used for decades in paint formulations and resin applications. ${ }^{9}$ Plant oils or vegetable oils are fats derived in large volumes from agricultural feedstocks including plants seeds, as triglyceride esters of glycerol and 3 fatty acids. ${ }^{\mathbf{1 0 - 1 4}}$ In 2017/2018, global oil seed production (copra, cottonseed, palm kernel, peanut, rapeseed, soybean and sunflower seed) was estimated to be up to 574 million tonnes, accounting for 345 million tonnes of soybean oil. ${ }^{15}$

Soybean oil is used in various applications such as soaps, paints, coatings, lubricants, and bioplastics. ${ }^{16,17}$ Typically, soybean oil is composed of palmitic (11\%), oleic (23\%), linoleic (53\%), linolenic $(8 \%)$ fatty acids, having an average of 4.6

Materials Chemistry Research Center, Department of Chemistry, Center of Excellence for Innovation in Chemistry, Faculty of Science, Khon Kaen University, Khon Kaen 40002, Thailand. E-mail: nontsu@kku.ac.th

$\dagger$ Electronic supplementary information (ESI) available. See DOI: 10.1039/c8ra07133k double bonds per triglyceride., ${ }^{9,18,19}$ The abundance of unsaturated $\mathrm{C}=\mathrm{C}$ double bonds within the fatty acid constituents of soybean oil facilitate the production of epoxidised soybean oil (ESO). ${ }^{20}$ ESO can be easily transformed to epoxy thermosets through cationic polymerisation or curing with crosslinking agents such as dicarboxylic acid, anhydrides and diamines. ${ }^{\mathbf{1 4 2 1 - 2 5}}$ Moreover, ESO derived thermosets materials can be biodegradable in a composting environment. ${ }^{26}$ Although numerous studies of ESO based thermosets have been reported, the majority of work concerns the use of non-renewable crosslinkers, resulting in low bio-content products. ${ }^{27-29}$

The main challenge in converting ESO thermosets to high performance materials is to overcome the limitation of their short-chain crosslinked structures, which results in a brittle material. ${ }^{30}$ Long chain dicarboxylic acids have shown promising results when used as crosslinking agents for ESO, providing better flexibility and higher thermal stability as compared to those with shorter chains. ${ }^{\mathbf{1 4 , 3 1}}$ Several studies have developed bio-based crosslinkers for ESO resins to improve properties by providing a larger and stronger structural crosslinkers, such as the preparation of tetrafunctional crosslinkers from gallic acid dicarboxyl terminated oligomeric poly(butylene succinate) (OPBS) and dicarboxyl-terminated polyamide 1010 oligomers (NYL) from castor oil, which can enhance the mechanical properties for ESO-based thermoset materials. ${ }^{32-34}$ Dai et al. reported a synthesis of polyesters by melt polycondensation of itaconic acid with diols and glycerol, which were used to crosslink acrylated epoxidized soybean oil (AESO). The results 
indicated that the introduction of the polyesters significantly improved the mechanical properties of the thermosetting resins. ${ }^{35}$ Other bio-derived crosslinkers including methacrylated eugenol and isosorbide-methacrylate were also utilised as hardeners for AESO, ${ }^{36,37}$ however such crosslinkers are not fully bio-based and are costly. Therefore, further work is still needed to develop commercially viable sustainable low cost crosslinkers from abundantly available bio-based platform molecules. Glycerol is an abundant co-product of the biodiesel industry and one of the top 12 bio-derived platform molecules. ${ }^{3,38}$

Herein, carboxylic hyperbranched oligomers (Gly-SA) crosslinking agents have been synthesised via a simple esterification reaction of glycerol (Gly) and succinic anhydride (SA). These bioderived crosslinkers were utilised in the curing of ESO in order to obtain a fully bio-based thermosetting resin.

\section{Experimental}

\section{Materials}

Epoxidised soybean oil (ESO) was purchased from Akcros Chemicals as Lankroflex E2307. Glycerol (Gly, 99.5\%) was purchased from Carlo erba. Succinic anhydride (SA, 98\%) was supplied from Merck. 4-Dimethylaminopyridine (DMAP, 99\%) was obtained from Acros Chemicals. All materials were used as received without further purification.

\section{Synthesis of carboxyl-terminated hyperbranched oligomers}

Carboxyl-terminated crosslinkers with different molecular weights were synthesised by direct esterification of glycerol and succinic anhydride. Four different temperatures; $90{ }^{\circ} \mathrm{C}, 110{ }^{\circ} \mathrm{C}$, $130{ }^{\circ} \mathrm{C}$ and $150{ }^{\circ} \mathrm{C}$ of the synthesis temperature were used and the products obtained were named according to their processing temperatures as Gly-SA90, Gly-SA110, Gly-SA130, and GlySA150, respectively. The Gly-SA crosslinkers were synthesised according to Scheme 1 from glycerol and succinic anhydride in a molar ratio of $1: 3$ at four different temperatures for 5 hours under a nitrogen atmosphere and the obtained materials were stored at room temperature.

NMR of Gly-SA: ${ }^{1} \mathrm{H}$ NMR (DMSO, $\left.\delta, \mathrm{ppm}\right): 2.4-2.6\left(\mathrm{CH}_{2}-\right.$ $\mathrm{COOH}$ and $\left.\mathrm{CH}_{2}-\mathrm{COO}-\right)$, 3.9-4.2 (- $\left.\mathrm{CH}_{2}-\mathrm{OCO}-\right)$, 5.1-5.2 (-CH-O$\mathrm{CO}-) ;{ }^{13} \mathrm{C}$ NMR (DMSO, $\left.\delta, \mathrm{ppm}\right): 29.0\left(-\mathrm{CH}_{2}-\mathrm{COOH} \&-\mathrm{CH}_{2}-\right.$ COO-), 62.1 (- $\left.\mathrm{CH}_{2}-\mathrm{OCO}-\right)$, 69.3 (-CH-O-CO-), 172.2 (-COO-), $173.6(-\mathrm{COOH}){ }^{39}$

\section{Preparation of sample films of Gly-SA cured ESO thermosets}

Bio-based thermosetting films were prepared by ring-opening crosslinking reaction of ESO with Gly-SA. Gly-SA was melted at $140{ }^{\circ} \mathrm{C}$ for 5 minutes, to this ESO was added to the mixture solution (1: 1 weight ratio) and stirred for 15 minutes at $140{ }^{\circ} \mathrm{C}$. Subsequently, DMAP catalyst ( $0.5 \%$ of the total resin weight) was added and the mixture was stirred for a further 2 minutes. The mixture was poured into a silicone tray and cured at $140{ }^{\circ} \mathrm{C}$ for 24 hours in order to obtain the thermoset materials (EGS). The plausible cross-linked structure of the EGS resin is presented in Scheme 2.

\section{Characterisation}

Infrared spectroscopy. Infrared spectra was recorded using a Bruker TENSOR 27 in attenuated total reflectance (ATR) mode with Opus 7.0 software measuring in the range of 4000$550 \mathrm{~cm}^{-1}$, using a resolution of $1 \mathrm{~cm}^{-1}$ and 16 scans.

${ }^{1} \mathrm{H}$ NMR and ${ }^{13} \mathrm{C}$ NMR. ${ }^{1} \mathrm{H}$ NMR and ${ }^{13} \mathrm{C}$ NMR spectra were recorded using a Varian $400 \mathrm{MHz}$ NMR spectrometer using deuterated dimethyl sulfoxide ( $\mathrm{d}^{6}$-DMSO) as the solvent.

Molecular weight and polydispersity index of Gly-SA. Gel permeation chromatography (GPC) was used to determine the molecular weight of synthesised crosslinkers. The study was performed on a Shimadzu LC-20AD with CTO-20A oven column and a RID-10A detector, equipped with a Shodex KF-804L
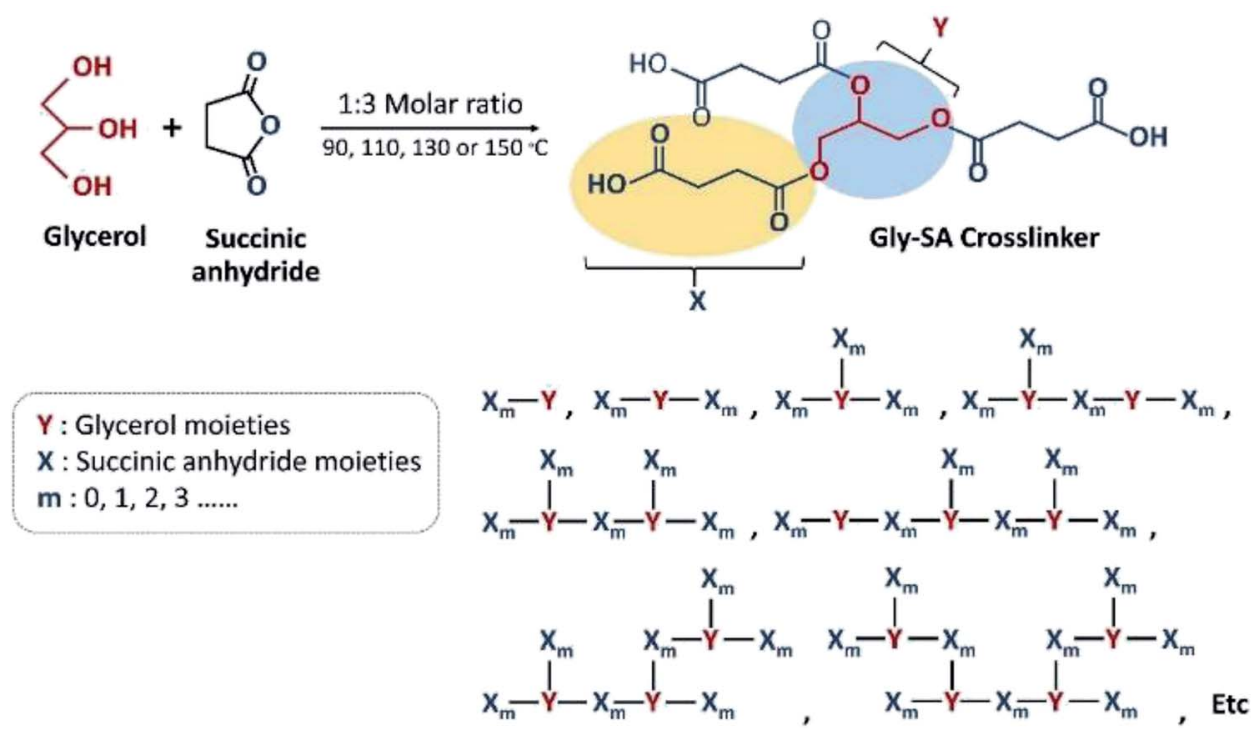

Scheme 1 Schematic representation of synthetic route to Gly-SA crosslinker. 


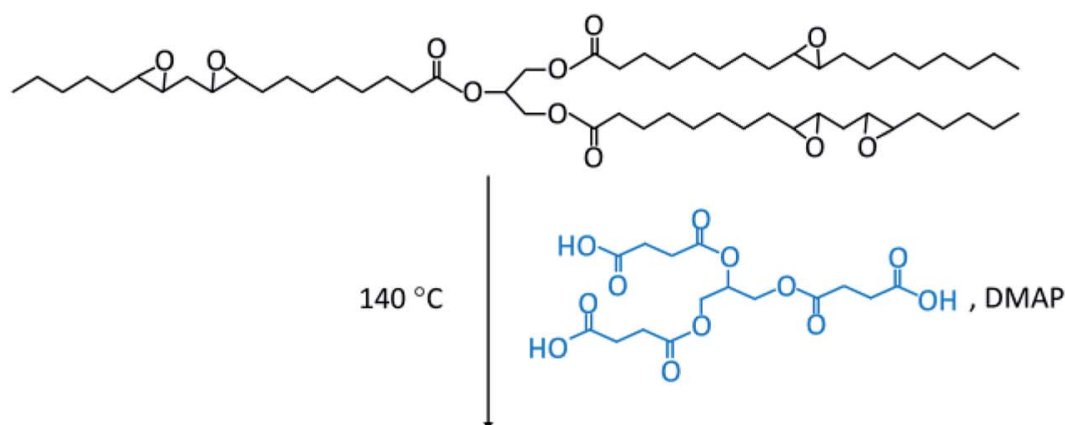

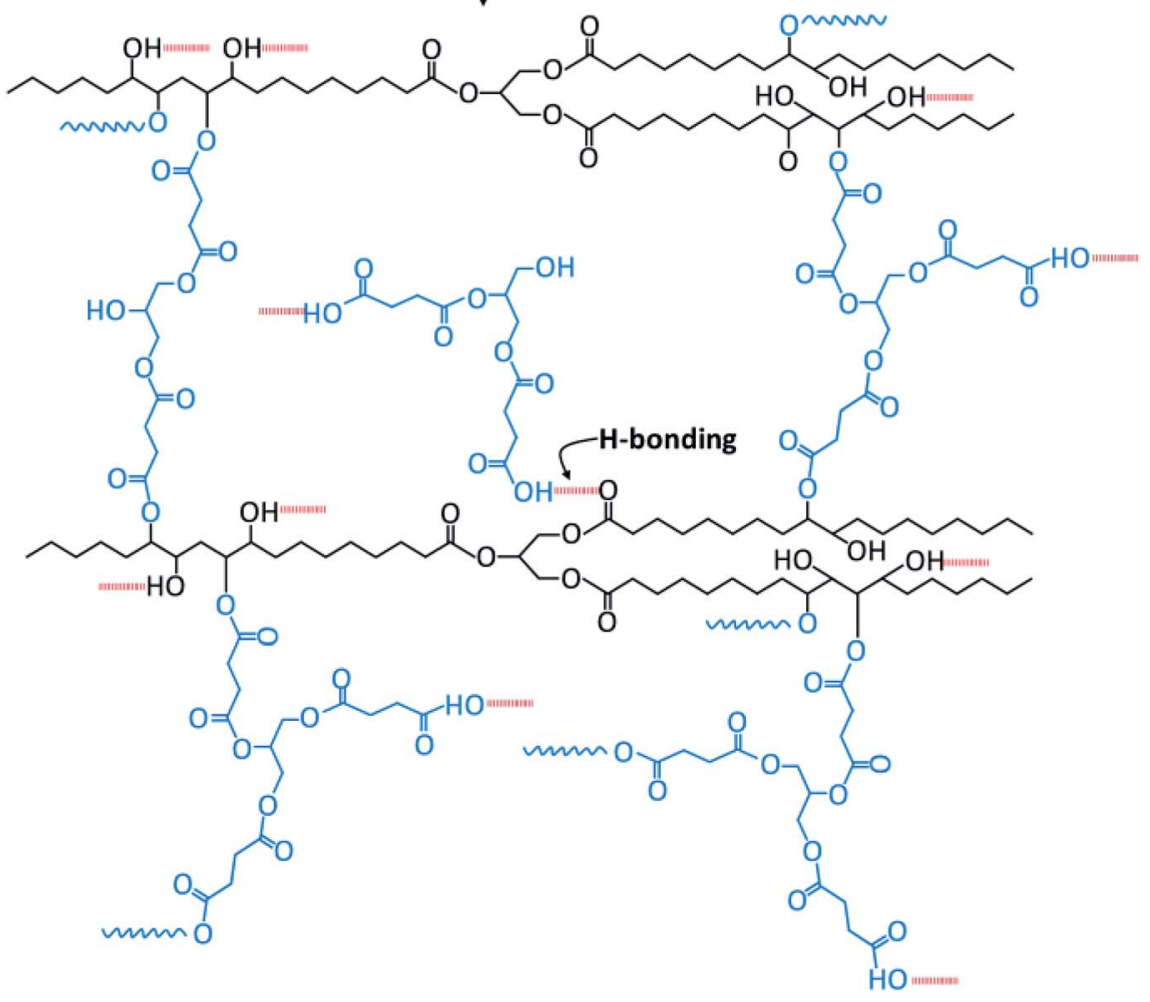

Scheme 2 Plausible crosslinked structure for the ESO with Gly-SA.

column. THF was used as the mobile phase at the flow rate of 1 $\mathrm{mL} \min ^{-1}$ at $25^{\circ} \mathrm{C}$. Poly(methyl methacrylate) (PMMA) standard was used for molecular weight calibration. The data was processed using the Class VP programme provided by Shimadzu.

Thermogravimetric analysis (TGA). The decomposition temperature of crosslinkers, ESO-Gly-SA mixtures and cured polymer films were determined using a Hitachi STA720 Thermal Analyser. The samples were heated at $10{ }^{\circ} \mathrm{C} \mathrm{min}^{-1}$ from room temperature to $550{ }^{\circ} \mathrm{C}$ under a nitrogen atmosphere. The initial sample weight was $10-15 \mathrm{mg}$.

MDSC of reaction mixture. Reaction mixtures were investigated using a TA Q2000 modulated differential scanning calorimeter (MDSC). The mixtures were accurately weighted $(10 \mathrm{mg})$ in to high pressure stainless steel pans, sealed and subjected to a heat-cool cycle from $-80{ }^{\circ} \mathrm{C}$ to $+250{ }^{\circ} \mathrm{C}$ at $1{ }^{\circ} \mathrm{C} \min ^{-1}$ with a modulation cycle of $\pm 0.5{ }^{\circ} \mathrm{C}$ every 200 seconds.

Mechanical test. The resulting films were cut into standard dumb-bell shapes $(60 \mathrm{~mm} \times 10 \mathrm{~mm})$. The elastic modulus, tensile strength, and elongation at break of the cured films were studied using Instron 5567A universal testing machine fitted with $1000 \mathrm{~N}$ capacity load cell. The initial grip separation was set at $35 \mathrm{~mm}$ and the crosshead speed was $20 \mathrm{~mm} \mathrm{~min}^{-1}$. The results reported were the averages of the three measurements.

Thermal ageing study. Thermal ageing study was performed in an oven operated at $80{ }^{\circ} \mathrm{C}$ for 7 days. After reconditioning at room temperature for 24 hours, the aged specimen were tested by tensile testing using the same procedures as mentioned above in order to determine the effect of ageing process on the mechanical properties.

Dynamic mechanical analysis. Dynamic mechanical analysis (DMA) of the cured films was carried out in tensile mode on a TAQ800, PerkinElmer. The sample were cut into a $10 \times$ $40 \mathrm{~mm}$ and then heated from $-60{ }^{\circ} \mathrm{C}$ to $100{ }^{\circ} \mathrm{C}$ at a scanning rate of $10^{\circ} \mathrm{C} \mathrm{min}{ }^{-1}$, frequency of $1 \mathrm{~Hz}$ and oscillation amplitude of $0.1 \mathrm{~mm}$. Storage modulus $\left(E^{\prime}\right)$ and $\tan \delta$ as a function of temperature at a constant frequency were observed.

Oxidative stability. Oxidative stability of films was determined by measuring the residual weight (\%) of the films whilst 
soaking in Fenton's reagent $\left(2 \mathrm{ppm}^{\mathrm{FeSO}_{4}}\right.$ in $3 \mathrm{wt} \% \mathrm{H}_{2} \mathrm{O}_{2}$ solution). The films $\left(1 \times 1 \mathrm{~cm}^{2}\right)$ were soaked in Fenton's reagent at $80{ }^{\circ} \mathrm{C}$ for $1 \mathrm{~h}$. The residual weight $\left(R_{\mathrm{W}}\right)$ was calculated using the formulation:

$$
R_{\mathrm{W}}(\%)=\frac{W_{\text {dry }, \mathrm{t}}}{W_{\text {dry,i }}} \times 100
$$

where $W_{\text {dry,i }}$ and $W_{\text {dry,t }}$ are the dry weight $(\mathrm{g})$ before and after treatment in Fenton's reagent, respectively.

\section{Results and discussion}

\section{Synthesis and characterisation of Gly-SA}

A schematic representation of the synthesis of Gly-SA crosslinkers and the possibility of the hyperbranched chain is shown in Scheme 1. The obtained products are viscous liquids at room temperature with white to pale yellow colour as shown in Fig. 1.

Fourier transform infrared (FTIR) spectroscopy was used in attenuated total reflectance (ATR) mode to investigate the reaction between glycerol and succinic anhydride. The FTIR spectra of glycerol, succinic anhydride and Gly-SA are shown in Fig. 2. The disappearance of the anhydride bands at 1775 and $1862 \mathrm{~cm}^{-1}$ confirmed the ring opening reaction of the anhydride. The $\mathrm{C}=\mathrm{O}$ characteristic bands at 1707 and $1730 \mathrm{~cm}^{-1}$ were noted in the spectra of the synthesised crosslinkers, suggesting the presence of carboxylic acid and ester functionalities respectively. Notably, the absorption peak at $1153 \mathrm{~cm}^{-1}$ associated with the $\mathrm{C}-\mathrm{O}$ stretching vibration indicated the esterification of glycerol and succinic anhydride. FTIR results for GlySA90, Gly-SA110 and Gly-SA130 are consistent with the results of Gly-SA150 and are presented in the ESI. $\dagger$

The structures of Gly-SA were further supported by ${ }^{1} \mathrm{H}$ and ${ }^{13} \mathrm{C}$ NMR spectroscopy. The ${ }^{1} \mathrm{H}$ and ${ }^{13} \mathrm{C}$ NMR spectra of GlySA90, Gly-SA110, Gly-SA130 and Gly-SA150 are shown in Fig. 3 and 4 , respectively. The incorporation of hyperbranched units of the crosslinkers was noted as point (e) in ${ }^{1} \mathrm{H}$ NMR spectra, corresponding to the further esterification reactions of carboxylic acid end groups and hydroxyl group in glycerol molecules (ESI Fig. S2 $\dagger$ ). The intensity of the peak was found to increase with increasing preparation temperature, indicating the increase in the degree of branching.

\section{Molecular weight of Gly-SA crosslinkers}

The molecular weights of Gly-SA were determined by gel permeation chromatography (GPC) using THF as the mobile

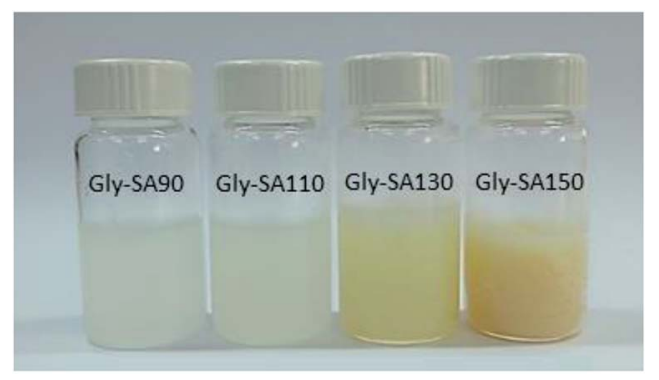

Fig. 1 Gly-SA crosslinkers.

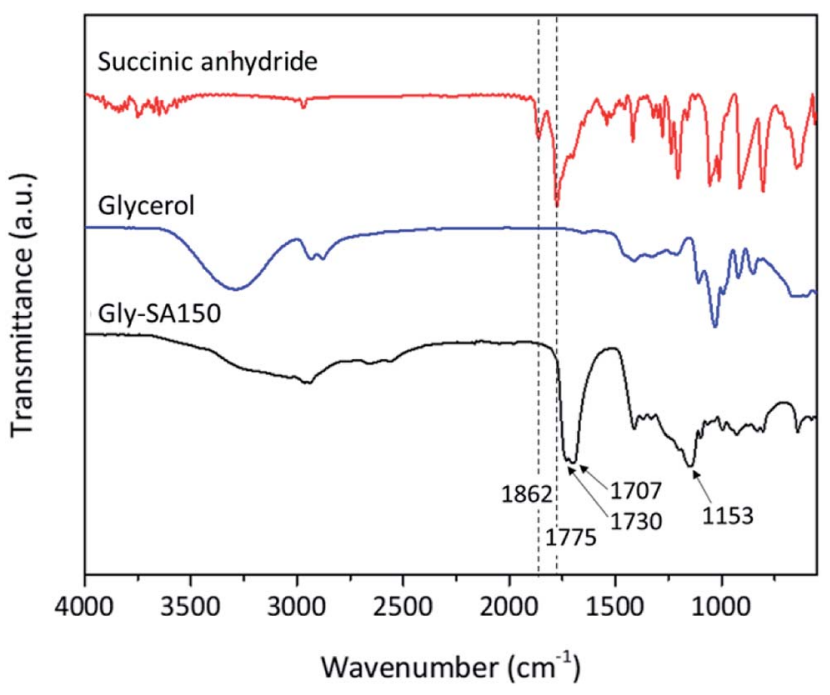

Fig. 2 FTIR spectra of glycerol, succinic anhydride and Gly-SA150.

phase. The GPC chromatographs of Gly-SA90, Gly-SA110, GlySA130 and Gly-SA150 are shown in Fig. 5.

The peaks of Gly-SA prepared at high temperature were much broader than those of Gly-SA prepared at lower temperature and shifted to shorter retention times owing to the growth of molecular weight. The GPC curves indicated that the products were composed of at least four macromolecular populations and the evolution of the populations with the temperature was clearly seen.

\section{Thermal stability of Gly-SA crosslinkers}

TGA and DTG thermograms of Gly-SA crosslinkers were shown in Fig. 6. All Gly-SA crosslinkers exhibited a small loss of water, however a greater loss is observed at preparation temperatures of $130{ }^{\circ} \mathrm{C}$ (Gly-SA130) and $150{ }^{\circ} \mathrm{C}$ (Gly-SA150), due to the increased degree of esterification. The second weight loss was observed between $160{ }^{\circ} \mathrm{C}$ and $330{ }^{\circ} \mathrm{C}$ resulting from the degradation of the remaining succinic anhydride and glycerol in the crosslinked mixture..$^{\mathbf{4 0}-42}$ The weight loss between $330{ }^{\circ} \mathrm{C}$ and

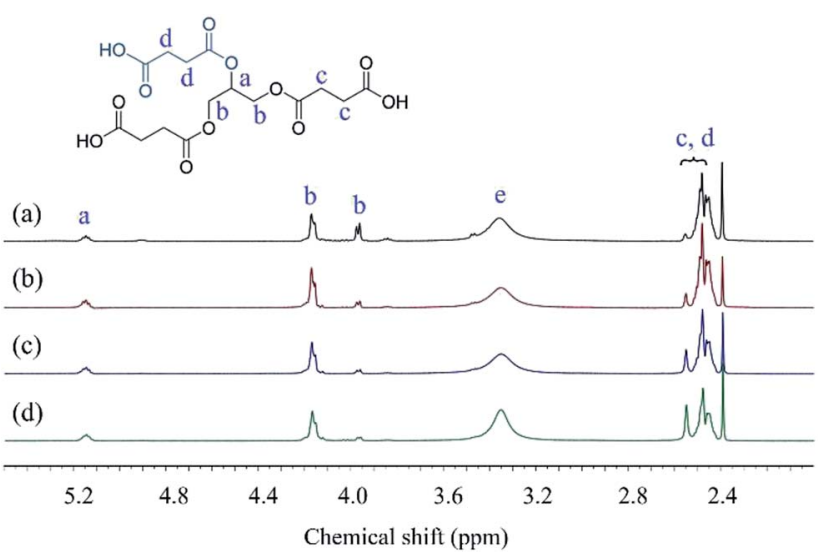

Fig. $3{ }^{1} \mathrm{H}$ NMR spectra of (a) Gly-SA90, (b) Gly-SA110, (c) Gly-SA130 and (d) Gly-SA150. 


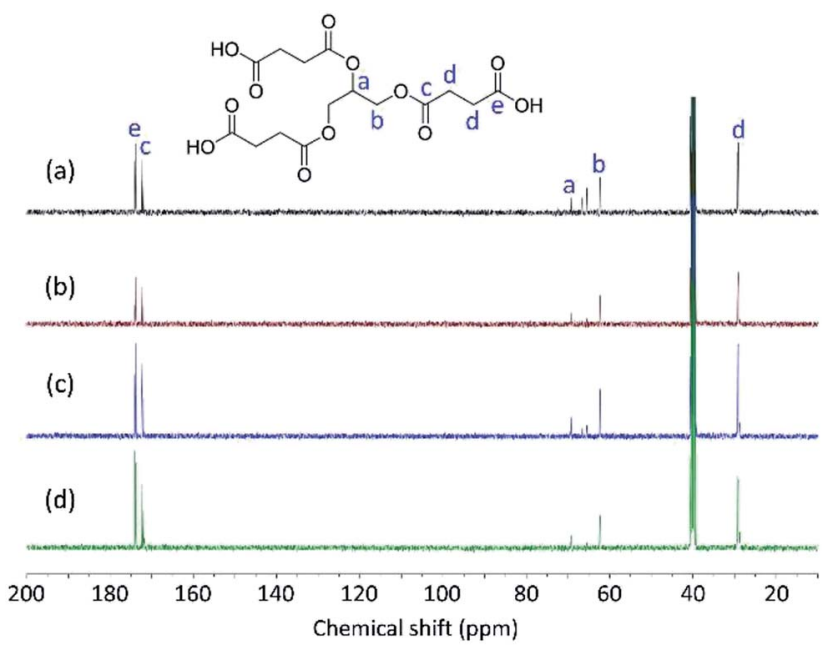

Fig. $4{ }^{13}$ C NMR spectra of (a) Gly-SA90, (b) Gly-SA110, (c) Gly-SA130 and (d) Gly-SA150.
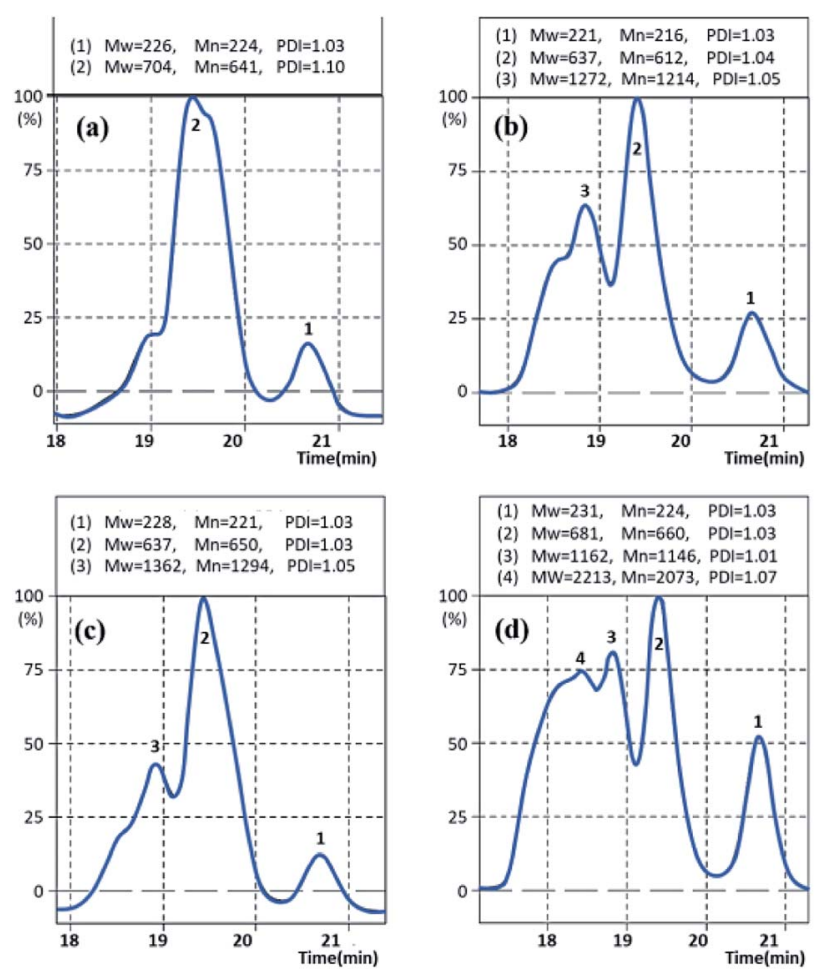

Fig. 5 GPC curves of (a) Gly-SA90, (b) Gly-SA110, (c) Gly-SA130 and (d) Gly-SA150

$430{ }^{\circ} \mathrm{C}$ was attributed to the decomposition of the main crosslinker chains with carboxyl-terminated groups.

The DTG thermograms (Fig. 6b) revealed that the rate of degradation of Gly-SA crosslinkers increased with decreasing preparation temperature. Furthermore, a shift of the maximum decomposition rate to higher temperature was noted on increasing preparation temperature. This is likely due to the higher molecular weight and greater degree of entanglement of the crosslinkers obtained from higher preparation temperatures. ${ }^{43}$
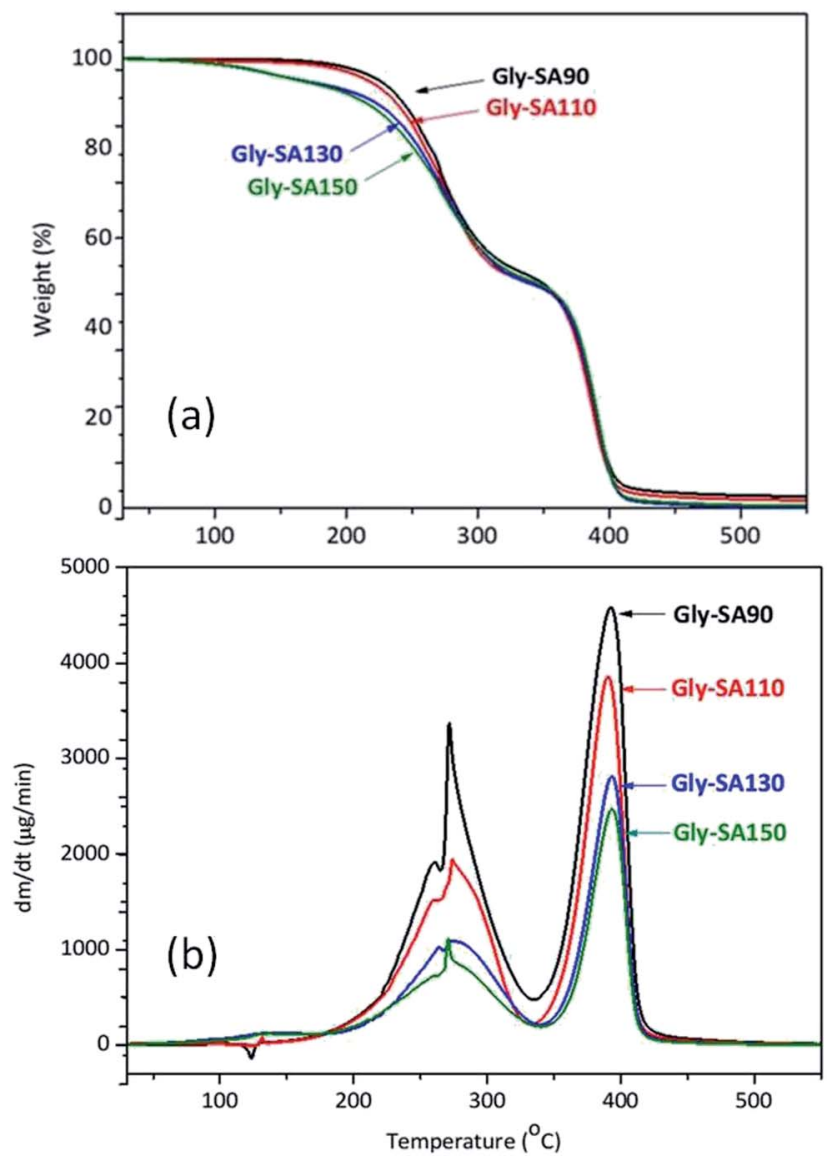

Fig. 6 TGA (a) and DTG (b) curves of Gly-SA crosslinkers.

\section{Preparation and characterisation of Gly-SA cured ESO thermosets}

The synthesised Gly-SA materials were used as crosslinkers for the curing of epoxidised soybean oil (ESO). The envisaged curing reaction of ESO with Gly-SA crosslinkers is the ring opening of epoxide by deprotonated carboxylic acid attacking of carboxyl groups to create a network structure shown in Scheme $2 .^{26}$ Preparation of films from cured mixtures in silicone moulds at $140{ }^{\circ} \mathrm{C}$ produced films with the thickness of $1 \mathrm{~mm}$. The obtained thermoset materials were noted as EGS90, EGS110, EGS130 and EGS150 according to crosslinkers used in the formulations (Gly-SA90, Gly-SA110, Gly-SA130 and Gly-SA150, respectively). Fig. 7 exhibits the ESO based films cured at 4 and 24 hours.

The ESO homopolymer was still not cured after 4 hours. The ESO-Gly-SA films cured for 4 hours showed similar yellow colour as that of ESO homopolymer film, however, those cured for 24 hours showed a darker colour. All films were flexible and transparent as demonstrated in Fig. 8.

It is envisaged that at the beginning of the cure process deprotonation of any acid group(s) in crosslinkers occurs. The resulting carboxylate ion then acts as a nucleophile in the ringopening of the epoxide, leading to alkoxide formation and protonated to form an alcohol. The base catalysts assist the proton transfer in the system. The alcohol functionalities 


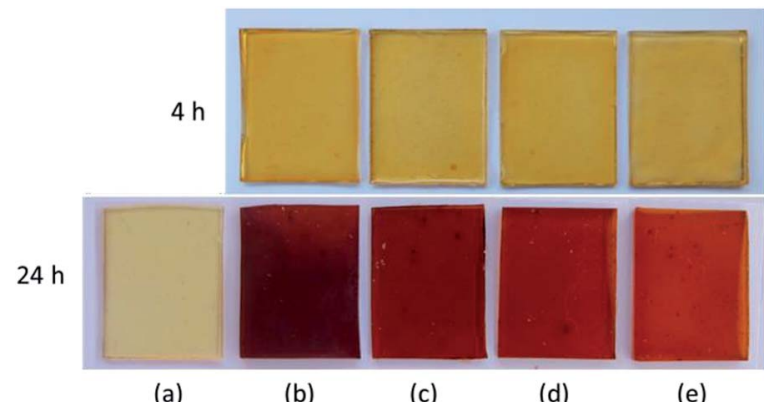

(a)

(b)

(c)

(d)

(e)

Fig. 7 Photographs of cured ESO based films (a) ESO homopolymer, (b) EGS90, (c) EGS110, (d) EGS130 and (e) EGS150.

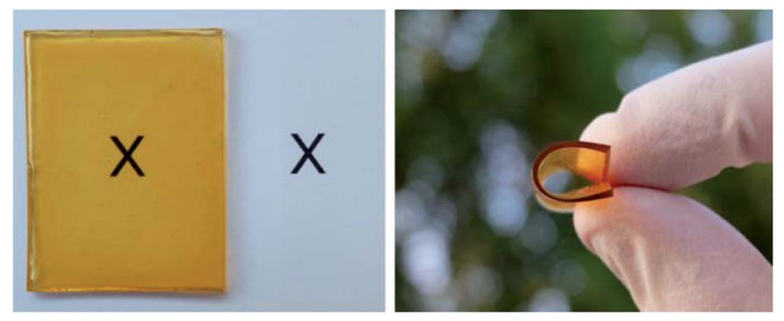

Fig. 8 Transparent and flexible EGS150 film.

present in the crosslinker and formed in curing can further react with epoxide to create the polymer network. Such reactions are consistent with those previously reported for the cross linking of epoxidised oils with diacids..$^{44}$ These observations are also backed up with FTIR results.

The crosslinking of ESO and Gly-SA via esterification reaction was studied using ATR-FTIR technique. The FTIR spectra of EGS films are shown in Fig. 9. In the FTIR spectra of all EGS films, the intensity of the band at $830 \mathrm{~cm}^{-1}$ ascribed as the epoxy group decreased due to the ESO ring opening polymerisation reaction by Gly-SA crosslinkers. The band at $3465 \mathrm{~cm}^{-1}$ associating to the hydroxyl functionality was also noted as evidence of epoxide ring opening. A new band at $1003 \mathrm{~cm}^{-1}$ was observed indicating the presence of ether functionality, suggesting possible etherification of the alkoxide group that can subsequently react with other epoxides and contribute to the formation of the crosslinked network.

Furthermore, the band at $1711 \mathrm{~cm}^{-1}$ corresponding to the carbonyl group of carboxylic acid observed in Gly-SA crosslinkers was no longer present in the EGS films, providing further evidence of crosslinking through this functionality. This was also confirmed by the shift of the ester band, from $1741 \mathrm{~cm}^{-1}$ for the ESO spectrum to $1729 \mathrm{~cm}^{-1}$ in the thermosets spectra.

\section{Thermal analysis of EGS mixtures and EGS films}

Modulated DSC was utilised to study thermal events occurring during the curing process of the bio-based thermosets. An exothermic transition was observed in all mixture samples during the first heating run (Fig. 10).

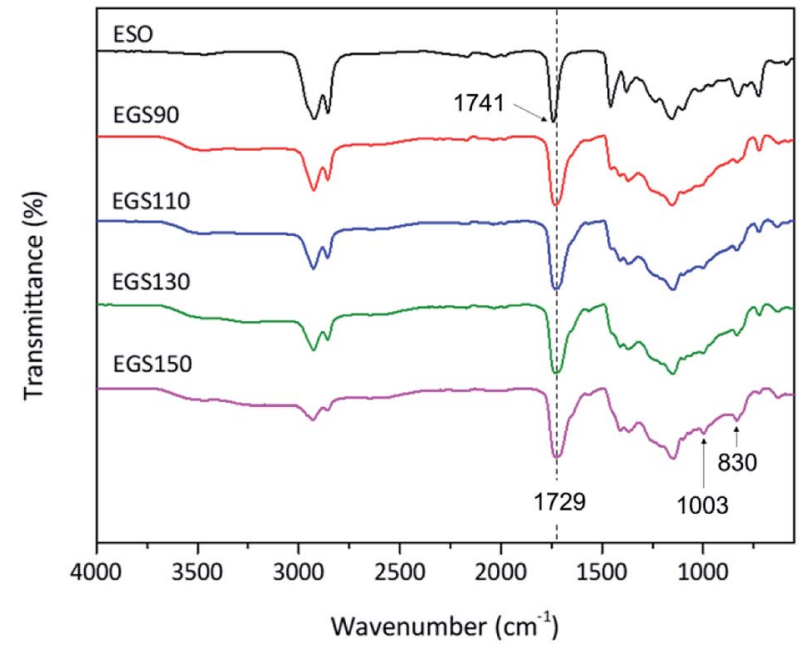

Fig. 9 FTIR spectra of ESO and EGS films.

The analysis showed that the different crosslinkers scarcely affect the peak temperature of the curing process however, the onset temperature tends to rise with increased crosslinker chain length (Table 1). This was anticipated as the steric hindrance can be expected when longer chains are present in the formulation, resulting in retardation of the curing process. The total heat of the reaction of the curing process decreased with increasing chain-length of Gly-SA crosslinkers (Table 1), suggesting less crosslinking occurred. This was probably due to the availability of reactive groups.

The glass transition $\left(T_{\mathrm{g}}\right)$ of EGS films were analysed by DSC. Fig. 11 shows the second heating scan of EGS films, $T_{g}$ shifted to higher temperature with increasing chain-length of Gly-SA to $-20.59,-19.44,-18.89$ and $-15.83{ }^{\circ} \mathrm{C}$ for EGS90, EGS110, EGS130 and EGS150, respectively, which is explained by the increased molecular weight of Gly-SA.

The films with crosslinkers prepared from higher temperature showed higher glass transition temperature but

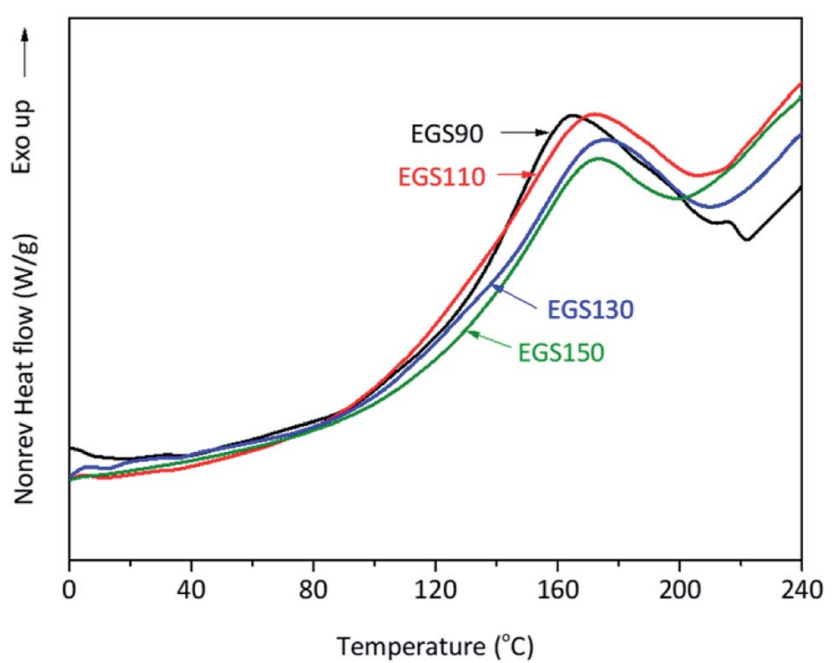

Fig. 10 DSC thermograms of crosslinking ESO formed by reaction between ESO and Gly-SA different chain-length. 
Table 1 MDSC results of EGS mixtures and EGS films

\begin{tabular}{|c|c|c|c|c|}
\hline Resin & $\begin{array}{l}\text { Total heat of } \\
\text { reaction }\left(\mathrm{J} \mathrm{g}^{-1}\right)\end{array}$ & $\begin{array}{l}\text { Onset temperature } \\
\left({ }^{\circ} \mathrm{C}\right)\end{array}$ & $\begin{array}{l}\text { Peak temperature } \\
\left({ }^{\circ} \mathrm{C}\right)\end{array}$ & $T_{\mathrm{g}}\left({ }^{\circ} \mathrm{C}\right)$ \\
\hline EGS90 & 140.0 & 123.1 & 163.0 & -20.59 \\
\hline EGS130 & 83.0 & 129.1 & 171.3 & -18.89 \\
\hline EGS150 & 49.9 & 133.0 & 169.9 & -15.83 \\
\hline
\end{tabular}

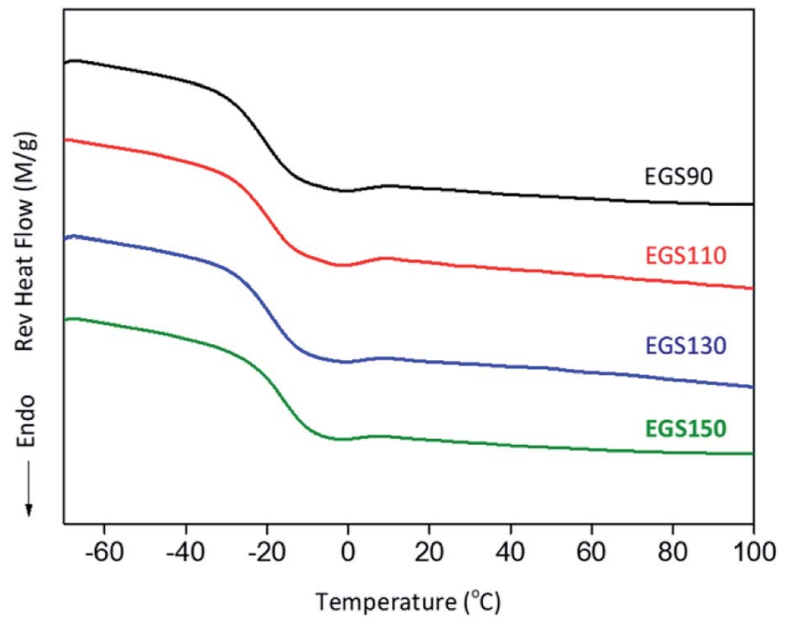

Fig. 11 DSC heating scans of different chain-length Gly-SA cured ESO.

highlighted that less crosslinking occurred during the curing process. At higher temperatures Gly-SA crosslinkers could further increase the chain length or even polymerise, leading to higher molecular weights as previously revealed by GPC results. The pre-polymerised crosslinkers contribute to the rise of glass transition in the final thermoset product.

\section{Mechanical properties}

The mechanical properties of the sample films were evaluated by tensile testing. Fig. 12 showed the stress-strain curves of the Gly-SA cured ESO (EGS) and cured ESO with DMAP which was used as a control sample. All samples used for tensile testing were cured at $140{ }^{\circ} \mathrm{C}$ for 24 hours. The control sample exhibited low mechanical properties with tensile strength $(\sigma)$ and elongation at break $(\varepsilon)$ of $183 \pm 7 \mathrm{kPa}$ and $14.1 \pm 0.3 \%$, respectively (Table 2). Films comprising of ESO, Gly-SA crosslinkers and DMAP demonstrated higher tensile strength, elongation at break and Young's modulus compared to those of the control. The tensile strength increased to $883 \pm 43,1203 \pm 32,1544 \pm$ 76 , and $2323 \pm 102 \mathrm{kPa}$ for EGS90, EGS110, EGS130, and EGS150, respectively with the EGS150 film demonstrating a tensile strength which is 13 times higher than that of the control film. The addition of the crosslinkers also enhanced the elongation at break of the materials with EGS150 exhibited more than $220 \%$ increase in elongation at break compared to that of the DMAP cured ESO sample. The Young's modulus of the samples with crosslinkers significantly increased to quadruple the value obtained for the control sample. It is noteworthy that the tensile strength and elongation at break increased with increasing Gly-SA chain length, suggesting the pre-polymerised crosslinkers contribute to the enhanced mechanical properties of the materials.

DMA plots between storage modulus $\left(E^{\prime}\right)$ versus temperature, and $\tan \delta$ versus temperature were provided in Fig. 13. The glass transition temperature (determined from the $\tan \delta$ peak temperature) shifted to higher temperature with increasing chain-length of Gly-SA (5.0, 5.1, 6.6 and $8.6{ }^{\circ} \mathrm{C}$ for EGS90, EGS110, EGS130 and EGS150, respectively). This is in good accordance with DSC results. The increase of the glass transition temperature gives further insight concerning the more dense structure of the thermosets prepared from larger crosslinkers due to the decrease in chain-end concentration. ${ }^{45}$ Storage moduli of EGS films were significantly higher than that of cured ESO (control sample). It was found that the $E^{\prime}$ increased as the molecular weight of the Gly-SA crosslinking agent increased. Storage moduli of all EGS films began to change noticeably at $-20{ }^{\circ} \mathrm{C}$. The reduced $E^{\prime}$ was due to glassy-torubbery state transitions in the sample. The storage moduli at different temperatures were listed in Table 3.

\section{Thermal ageing study}

The mechanical properties of materials after thermal ageing are reported in Table 2 . The Young's modulus clearly decreased after 7 days of ageing in a hot air oven for all samples. The tensile strength also decreased for the control sample, EGS90

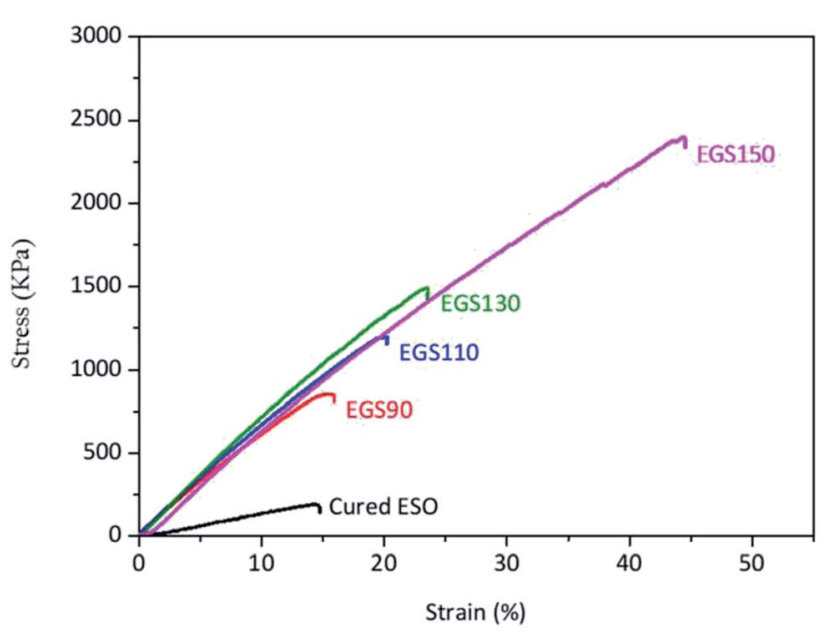

Fig. 12 Stress-strain curves of different chain-length Gly-SA cured ESO. 
Table 2 Mechanical properties of the thermoset films

\begin{tabular}{lllll}
\hline Properties & Control & EGS90 & EGS110 & EGS130 \\
\hline Before ageing & & & & EGS150 \\
Tensile strength (kPa) & $183 \pm 7$ & $883 \pm 43$ & $1204 \pm 32$ & $1544 \pm 76$ \\
Elongation at break (\%) & $14.1 \pm 0.3$ & $16.1 \pm 0.7$ & $20.5 \pm 1.1$ & $25.6 \pm 1.8$ \\
Young's modulus (MPa) & $1.5 \pm 0.1$ & $6.5 \pm 0.0$ & $7.1 \pm 0.2$ & $7.2 \pm 0.5$ \\
& & & & \\
After ageing & $96 \pm 8$ & $818 \pm 88$ & $1484 \pm 30$ & $1679 \pm 154$ \\
Tensile strength (kPa) & $16.5 \pm 2.4$ & $35.4 \pm 1.9$ & $65.7 \pm 1.2$ & $58.9 \pm 2.6$ \\
Elongation at break (\%) & $0.8 \pm 0.1$ & $3.6 \pm 0.5$ & $3.4 \pm 0.2$ & $4.5 \pm 0.4$
\end{tabular}
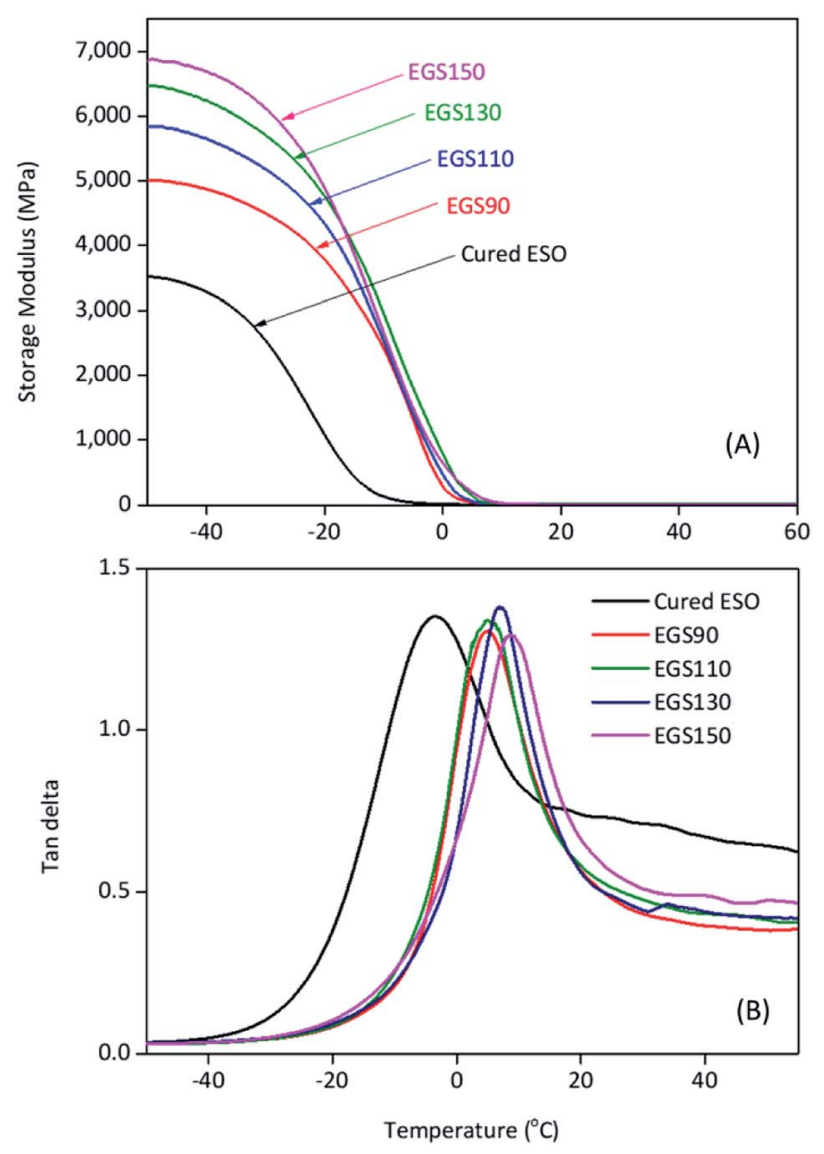

Fig. 13 Storage modulus (A) and $\tan \delta$ (B) curves of different chainlength Gly-SA cured ESO.

Table 3 Storage modulus and $\tan \delta$ results of EGS films

\begin{tabular}{lclll}
\hline & & \multicolumn{3}{l}{ Storage modulus (MPa) } \\
\cline { 4 - 5 } Sample & $\begin{array}{l}\tan \delta \\
\operatorname{peak}\left({ }^{\circ} \mathrm{C}\right)\end{array}$ & $-50{ }^{\circ} \mathrm{C}$ & $-25{ }^{\circ} \mathrm{C}$ & $0{ }^{\circ} \mathrm{C}$ \\
\hline Cured ESO & -3.4 & 3523 & 1864 & 15 \\
EGS90 & 5.0 & 5017 & 4203 & 285 \\
EGS110 & 5.1 & 5843 & 4834 & 459 \\
EGS130 & 6.6 & 6473 & 5311 & 777 \\
EGS150 & 8.6 & 6861 & 5612 & 636
\end{tabular}

and EGS150, however that of EGS110 and EGS130 slightly increased. This suggests that the curing of the formers were completed but the EGS110 and EGS130 may undergo the postcuring process. De Albuquerque et al. also noticed the slight increase in tensile strength after 4 days of thermal ageing, however the fall-off of the tensile strength was noted when the duration of thermal ageing was prolonged. ${ }^{46}$ The deterioration of the materials was due to oxidative degradation of the polymer. The elongation at break increased after the ageing process, due to the plasticising effect of water in the sample. ${ }^{47}$

\section{Thermal stability of EGS films}

The thermal stability of the EGS films were investigated by TGA under nitrogen atmosphere is shown in Fig. 14. The first stage of decomposition of the film was found between 160 and $330{ }^{\circ} \mathrm{C}$, which corresponds to the decomposition of succinic and glycerol remainder in the crosslinkers. These results strongly correlated with TGA data obtained for the crosslinkers, whereas at temperatures from 330 to $490{ }^{\circ} \mathrm{C}$ the decomposition of the crosslinked polymer network was observed.

\section{Oxidative stability}

During the use of the bio-based thermoset films in applications such as coating, oxygen may diffuse through the film leading to the degradation of thermoset polymer, most of which come from free radical damage. Oxidative stability of EGS films were therefore monitored by treating the films in the Fenton's reagent ( $2 \mathrm{ppm} \mathrm{FeSO}_{4}$ in $3 \mathrm{wt} \% \mathrm{H}_{2} \mathrm{O}_{2}$ solution) at $80^{\circ} \mathrm{C}$ for $1 \mathrm{~h}$. Fig. 15 demonstrates that all the EGS films exhibited the residual weight $\left(R_{\mathrm{W}}\right)$ in the region of $90-96 \%$.

The EGS film with a long chain crosslinking exhibited slightly lower oxidation stability than one with a short chain cross-linking. This was possibly due to the lower crosslinking density as suggested by lower total heat of reaction obtained from the DSC results. However, all of these bio-based thermosets are considered to demonstrate excellent oxidative resistance with the $R_{\mathrm{W}}$ of $96.0 \%, 95.3 \%, 93.7 \%$ and $91.2 \%$ for EGS90, EGS110, EGS130 and EGS150, respectively.

The crosslinkers and thermosets developed in this work offer a number of clear advantages to existing systems reported in the literature including being derived from abundant and low cost bio-derived feedstocks. Other reported crosslinkers are frequently only partially bio-derived, utilising expensive and low 

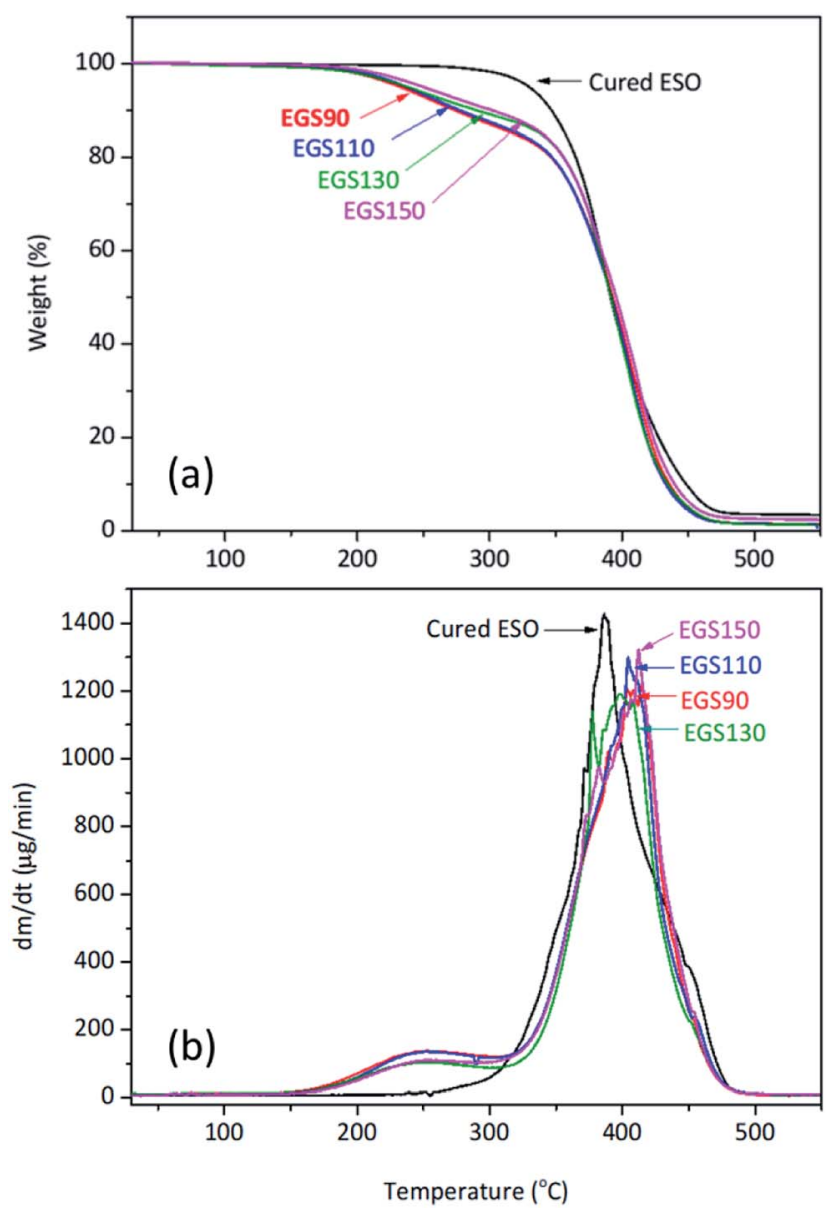

Fig. 14 TGA curves of different chain-length Gly-SA cured ESO.

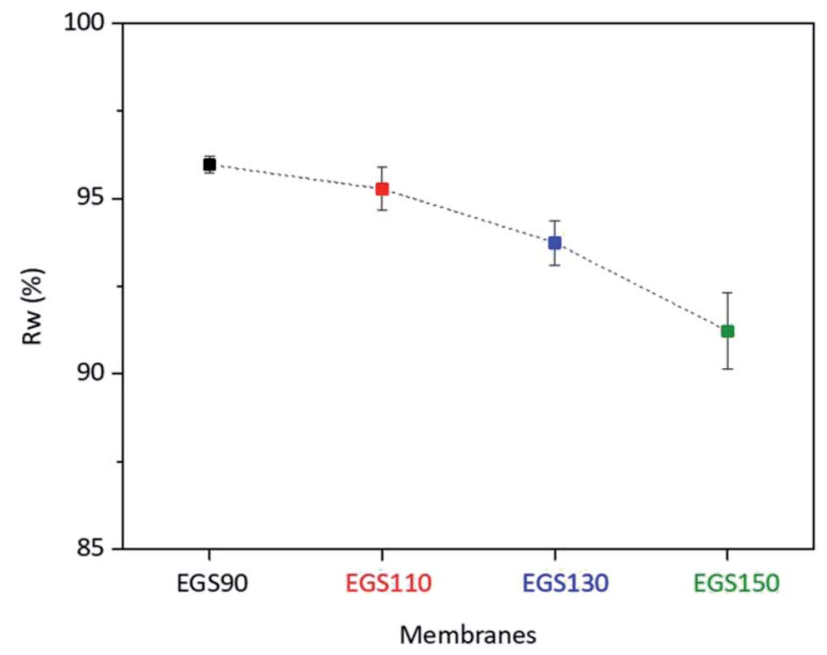

Fig. 15 Oxidative stabilities of EGS films.

volume feedstocks. ${ }^{27-29,36,37}$ This demonstrates a clear advantage of the EGS films, not only from an environmental standpoint but also from an economical perspective. This study also demonstrated the higher molecular weight crosslinkers, which can be obtained at increased preparation temperatures, led to materials with superior mechanical properties. The fully bio- based materials exhibit promising properties such high thermal stability and excellent oxidative resistance of more than $90 \%$, which is superior compared to other materials previously reported..$^{48,49}$ Previous literature has demonstrated limited focus on oxidative resistant properties of bio-based thermosets, this further highlights a distinct advantage of this study.

\section{Conclusions}

Fully bio-based thermoset materials have been synthesised from epoxidised soybean oil and bio-derived carboxylterminated hyperbranched crosslinkers. The crosslinkers were synthesised using the facile esterification reaction of glycerol with succinic anhydride (Gly-SA). The characterisation of the crosslinkers has shown that the molecular weight of the crosslinkers increased as the preparation temperatures increased, suggesting an introduction of hyperbranches to the molecules. FTIR and NMR techniques confirmed the presence of carboxylic acid functionality within the crosslinker molecules which allows the crosslinking with the epoxide of ESO. The obtained thermoset materials demonstrated high flexibility and transparency with excellent oxidative resistance. This study also investigated the effect of different molecular weights of Gly-SA on the thermal and mechanical properties of the thermoset films. DSC analysis revealed a slight decrease of the curing rate when the molecular weights of Gly-SA increase. The incorporation of the bulky of crosslinkers resulted in an increase of the glass transition temperature $\left(T_{\mathrm{g}}\right)$. The film produced from GlySA crosslinker prepared at $150{ }^{\circ} \mathrm{C}$ (EGS150) exhibited a tensile strength 13 times greater than that of the control film. Furthermore a $220 \%$ increase in elongation at break and a fourfold increase in Young's modulus compared to the values obtained from the control sample were noted. These results are in good accordance with those obtained from DMA study as the enhancement in $T_{\mathrm{g}}$ and storage moduli were also observed as the molecular weight of the crosslinking agent increased. Moreover these thermoset materials demonstrated excellent oxidative stability, ensuring a potential use of these materials in applications such as coating.

\section{Conflicts of interest}

There are no conflicts to declare.

\section{Acknowledgements}

This work was financially supported by the young researcher development project of Khon Kaen University. The authors would also like to thank Materials Chemistry Research Center and Center of Excellence for Innovation in Chemistry (PERCHCIC), Faculty of Science, Khon Kaen University.

\section{References}

1 A. Gandini and T. M. Lacerda, Prog. Polym. Sci., 2015, 48, 139. 
2 A. Corma, S. Iborra and A. Velty, Chem. Rev., 2007, 107, 24112502.

3 Y. Lu and R. C. Larock, ChemSusChem, 2009, 2, 136-147.

4 Z. Wang, X. Zhang, R. Wang, H. Kang, B. Qiao, J. Ma,

L. Zhang and H. Wang, Macromolecules, 2012, 45, 9010-9019.

5 Y. Xia and R. C. Larock, Green Chem., 2010, 12, 1893-1909.

6 B. M. Abdullah and J. Salimon, J. Appl. Sci., 2010, 10, 15451553.

7 U. Biermann, U. Bornscheuer, M. A. Meier, J. O. Metzger and H. J. Schäfer, Angew. Chem., Int. Ed., 2011, 50, 3854-3871.

8 N. Fox and G. Stachowiak, Tribol. Int., 2007, 40, 1035-1046.

9 R. Wool and X. S. Sun, Bio-based polymers and composites, Academic Press, 2011.

10 J. Espana, L. Sánchez-Nacher, T. Boronat, V. Fombuena and R. Balart, J. Am. Oil Chem. Soc., 2012, 89, 2067-2075.

11 P. Gogoi, H. Horo, M. Khannam and S. K. Dolui, Ind. Crops Prod., 2015, 76, 346-354.

12 T. Tsujimoto, T. Takayama and H. Uyama, Polymers, 2015, 7, 2165-2174.

13 T. Tsujimoto and H. Uyama, ACS Sustainable Chem. Eng., 2014, 2, 2057-2062.

14 R.-T. Zeng, Y. Wu, Y.-D. Li, M. Wang and J.-B. Zeng, Polym. Test., 2017, 57, 281-287.

15 R. Trostle, Global agricultural supply and demand: factors contributing to the recent increase in food commodity prices (rev), DIANE Publishing, 2010.

16 M. Flieger, M. Kantorova, A. Prell, T. Řezanka and J. Votruba, Folia Microbiol., 2003, 48, 27.

17 M. S. Lin, C. C. Liu and C. T. Lee, J. Appl. Polym. Sci., 1999, 72, 585-592.

18 F. I. Altuna, V. Pettarin and R. J. Williams, Green Chem., 2013, 15, 3360-3366.

19 F. Gunstone, Vegetable oils in food technology: composition, properties and uses, John Wiley \& Sons, 2011.

20 B. Cortese, M. H. de Croon and V. Hessel, Ind. Eng. Chem. Res., 2011, 51, 1680-1689.

21 S. Kocaman and G. Ahmetli, Prog. Org. Coat., 2016, 97, 53-64.

22 C. Öztürk and S. H. Küsefoğlu, J. Appl. Polym. Sci., 2011, 120, 116-123.

23 A. Ručigaj, B. Alič, M. Krajnc and U. Šebenik, Eur. Polym. J., 2014, 52, 105-116.

24 S. K. Sahoo, S. Mohanty and S. K. Nayak, Chin. J. Polym. Sci., 2015, 33, 137-152.

25 J. Xu, Z. Liu, S. Z. Erhan and C. J. Carriere, J. Am. Oil Chem. Soc., 2004, 81, 813-816.

26 W. Chow, S. Tan, Z. Ahmad, K. Chia, N. Lau and K. Sudesh, J. Polym. Environ., 2014, 22, 140-147.

27 J. D. Espinoza-Perez, B. A. Nerenz, D. M. Haagenson, Z. Chen, C. A. Ulven and D. P. Wiesenborn, Polym. Compos., 2011, 32, 1806-1816.
28 S. Tan, Z. Ahmad and W. Chow, Ind. Crops Prod., 2013, 43, 378-385.

29 S. Kumar, S. K. Samal, S. Mohanty and S. K. Nayak, Ind. Eng. Chem. Res., 2017, 56, 687-698.

30 M. Samper, V. Fombuena, T. Boronat, D. García-Sanoguera and R. Balart, J. Am. Oil Chem. Soc., 2012, 89, 1521-1528.

31 C. Ding, P. S. Shuttleworth, S. Makin, J. H. Clark and A. S. Matharu, Green Chem., 2015, 17, 4000-4008.

32 X.-Y. Jian, X.-P. An, Y.-D. Li, J.-H. Chen, M. Wang and J.-B. Zeng, Macromolecules, 2017, 50, 5729-5738.

33 X.-Y. Jian, Y. He, Y.-D. Li, M. Wang and J.-B. Zeng, Chem. Eng. J., 2017, 326, 875-885.

34 S. Ma, Y. Jiang, X. Liu, L. Fan and J. Zhu, RSC Adv., 2014, 4, 23036-23042.

35 J. Dai, S. Ma, Y. Wu, L. Han, L. Zhang, J. Zhu and X. Liu, Green Chem., 2015, 17, 2383-2392.

36 K. Liu, S. A. Madbouly and M. R. Kessler, Eur. Polym. J., 2015, 69, 16-28.

37 W. Liu, T. Xie and R. Qiu, ACS Sustainable Chem. Eng., 2016, 5, 774-783.

38 T. Werpy, G. Petersen, A. Aden, J. Bozell, J. Holladay, J. White, A. Manheim, D. Eliot, L. Lasure and S. Jones, Top value added chemicals from biomass. Volume 1-Results of screening for potential candidates from sugars and synthesis gas, Department of Energy Washington DC, 2004.

39 V. Somisetti, S. Allauddin, R. Narayan and K. Raju, RSC Adv., 2015, 5, 74003-74011.

40 C. Caires, L. Lima, C. Carvalho and M. Ionashiro, Ecletica Quim., 2010, 35, 73-80.

41 F. J. Caires, L. Lima, C. Carvalho and M. Ionashiro, Thermochim. Acta, 2010, 500, 6-12.

42 A. Gómez-Siurana, A. Marcilla, M. Beltrán, D. Berenguer, I. Martínez-Castellanos and S. Menargues, Thermochim. Acta, 2013, 573, 146-157.

43 F. Carrasco, P. Pagès, J. Gámez-Pérez, O. Santana and M. L. Maspoch, Polym. Degrad. Stab., 2010, 95, 116-125.

44 N. Supanchaiyamat, P. S. Shuttleworth, A. J. Hunt, J. H. Clark and A. S. Matharu, Green Chem., 2012, 14, 1759-1765.

45 A. Hale, C. W. Macosko and H. E. Bair, Macromolecules, 1991, 24, 2610-2621.

46 A. De Albuquerque, K. Joseph, L. H. de Carvalho and J. R. M. d'Almeida, Compos. Sci. Technol., 2000, 60, 833-844.

47 N. Esmaeili, F. O. Bakare, M. Skrifvars, S. J. Afshar and D. Åkesson, Cellulose, 2015, 22, 603-613.

48 T. Kamjornsupamitr, T. Sangthumchai, S. Youngme and S. Martwiset, Int. J. Hydrogen Energy, 2018, 43(24), 1119011201.

49 W. Liu, S. Wang, M. Xiao, D. Han and Y. Meng, Chem. Commun., 2012, 48, 3415-3417. 